\title{
The C. elegans homolog of the mammalian tumor suppressor Dep-1/Scc1 inhibits EGFR signaling to regulate binary cell fate decisions
}

\author{
Thomas A. Berset, Erika Fröhli Hoier, and Alex Hajnal ${ }^{1}$ \\ Institute of Zoology, University of Zürich, CH-8057 Zürich, Switzerland
}

\begin{abstract}
Protein phosphorylation by kinases and the subsequent dephosphorylation by phosphatases are key mechanisms that regulate intracellular signal transduction during development. Here, we report the identification of the receptor protein tyrosine phosphatase DEP-1 as a negative regulator of the Caenorhabditis elegans EGF receptor. DEP-1 amplifies in the developing vulva and the excretory system the small differences in the amount of EGF signal received by equivalent precursor cells to achieve binary cell fate decisions. During vulval development, DEP-1 inhibits EGFR signaling in the secondary cell lineage in parallel with the NOTCH-mediated lateral inhibition, while EGFR signaling simultaneously down-regulates DEP-1 and NOTCH expression in the primary cell lineage. This regulatory network of inhibitors results in the full activation of the EGFR/RAS/MAPK pathway in the primary vulval cells and at the same time keeps the EGFR/RAS/MAPK pathway inactive in the adjacent secondary cells. Mammalian Dep-1/Scc1 functions as a tumor-suppressor gene in the intestinal epithelium. Thus, mutations in human Dep-1 may promote tumor formation through a hyperactivation of the EGF receptor.
\end{abstract}

[Keywords: C. elegans; vulval development; EGFR; receptor protein tyrosine phosphatases; tumor suppressor]

Supplemental material is available at http://www.genesdev.org.

Received December 9, 2004; revised version accepted April 11, 2005.

Several components of the EGF receptor signal transduction pathway are phosphorylated when an EGF ligand binds to its receptor (for review, see Schlessinger 2000). In particular, autophosphorylation of the EGFR at specific intracellular tyrosine residues is critical for the subsequent signal transduction. Protein phosphatases may be part of a negative regulatory network that attenuates the activity of the EGFR/RAS/MAPK pathway. The genomes of both invertebrates and vertebrates encode a large number of predicted phosphatase genes (Bhaduri and Sowdhamini 2003; Alonso et al. 2004). For example, the Caenorhabditis elegans genome contains at least 165 putative protein phosphatase genes (http://www. wormbase.org). The physiological substrates of most protein phosphatases have not yet been identified, as many experiments addressing this question were performed in vitro or by overexpression, which often impairs the substrate specificity of phosphatases (den Hertog 1999; Blanchetot et al. 2005). Only a few protein phosphatases have been assigned specific roles in developmental processes

${ }^{1}$ Corresponding author.

E-MAIL ahajnal@zool.unizh.ch; FAX 41-1-6356878.

Article published online ahead of print. Article and publication date are at http://www.genesdev.org/cgi/doi/10.1101/gad.333505. or signaling pathways through clear-cut loss-of-function genetics. Examples include the mouse protein tyrosine phosphatase (PTP) 1B that inhibits insulin receptor signaling (Elchebly et al. 1999), Drosophila PTP-ER, which inhibits MAPK signaling during eye development (Karim and Rubin 1999) and C. elegans CLR-1, which inactivates the EGL-15 FGF receptor (Kokel et al. 1998). However, in many cases the identification and functional analysis of phosphatases is complicated by the fact that animals mutant for a single phosphatase gene display no obvious phenotype, suggesting that most protein phosphatases act redundantly (Harroch et al. 2000; Haj et al. 2003).

Mammalian Dep1 is a member of the class III Receptor Protein Tyrosine Phosphatase (R-PTP) family (den Hertog 1999). Dep-1 expression is induced in contact-inhibited cell cultures, hence the name Density-enhanced phosphatase 1 (Ostman et al. 1994). Different receptor tyrosine kinases (RTKs) including c-Met, PDGFR, and VEGFR-2 are Dep-1 substrates in vitro, but whether these RTKs are also in vivo substrates of Dep-1 is not known (Grazia Lampugnani et al. 2003; Jandt et al. 2003; Palka et al. 2003). Interestingly, Dep-1 exhibits tumorsuppressor activity when overexpressed in cultured tu- 
mor cells (Keane et al. 1996; Trapasso et al. 2000), and the mouse Dep-1 gene was recently identified as the colon cancer susceptibility locus scc1 (Ruivenkamp et al. 2002). Human Dep-1 is often mutated in colon, breast, skin, and lung carcinomas (Ruivenkamp et al. 2002). Despite its importance as a tumor suppressor in various epithelial tissues, the biological functions of Dep-1 are not understood. Numerous questions remain to be answered to elucidate the role of Dep-1 in tumorigenesis, including the identification of physiological substrates and the role of Dep-1 in cell fate specification and pattern formation during normal development.

The development of the $C$. elegans hermaphrodite vulva serves as a paradigm to study how equivalent precursor cells can integrate the input from multiple signaling pathways to achieve a binary cell fate decision (Sundaram 2004). During vulval induction, the anchor cell (AC) in the somatic gonad secretes the EGF-like growth factor LIN-3 to activate the EGFR/RAS/MAPK pathway in the adjacent vulval precursor cells (VPCs). The strength of the EGFR/RAS/MAPK signal in the VPCs depends on their distance from the AC (Yoo et al. 2004). The VPC located closest to the AC, P6.p, exhibits highest RAS/MAPK activity and adopts the primary $\left(1^{\circ}\right)$ cell fate. The neighboring VPCs, P5.p and P7.p, exhibit intermediate levels of RAS/MAPK activity (Yoo et al. 2004), and the distal VPCs P3.p, P4.p, and P8.p that are further away from the AC display weak RAS/MAPK activity due to a relay signal generated by the proximal VPCs (Dutt et al. 2004). However, by the time of vulval cell fate specification at the beginning of the L3 stage, a lateral signal from P6.p that is transduced by the DELTA/NOTCH signaling pathway inactivates the EGFR/RAS/MAPK pathway in P5.p and P7.p to prevent $1^{\circ}$ cell fate specification and induce the secondary $\left(2^{\circ}\right)$ fate in these cells (Ambros 1999; Berset et al. 2001; Chen and Greenwald 2004; Yoo et al. 2004). LIN-12 NOTCH signaling inhibits $1^{\circ}$ fate specification in P5.p and P7.p by up-regulating the transcription of several negative regulators of the EGFR/RAS/MAPK signaling pathway such as lip-1, dpy-23, and the 1st genes (Berset et al. 2001; Yoo et al. 2004). In particular, the dual-specificity phosphatase LIP-1, which is the homolog of vertebrate MKP3 , inactivates the MAP kinase MPK-1 to inhibit $1^{\circ}$ fate specification in P5.p and P7.p (Berset et al. 2001). However, lip-1(lf) or 1st RNA interference (RNAi) animals develop a morphologically wild-type vulva. Moreover, double mutants between lip-1(lf) and known inhibitors of the EGFR/RAS/MAPK signaling pathway such as unc101 (Lee et al. 1994), sli-1 (Yoon et al. 1995), gap-1 (Hajnal et al. 1997), or ark-1 (Hopper et al. 2000) display no visible defects in lateral inhibition (T. Berset and A. Hajnal, unpubl.). These observations suggested that lip-1 and the 1st genes act redundantly with other inhibitors of the EGFR/RAS/MAPK pathway to achieve the binary, $1^{\circ}$ versus $2^{\circ}$ cell fate decision in the VPCs.

Here, we report the identification of the C. elegans R-PTP dep-1 in a genetic screen for genes that regulate the $1^{\circ}$ versus $2^{\circ}$ cell fate decision during vulval development. DEP-1 negatively regulates LET-23 EGFR signal- ing in the vulva and the excretory system in parallel with the MAPK phosphatases LIP-1 and independently of LIN-12 NOTCH. Similar to mutations in the mammalian Dep-1/Scc1 tumor-suppressor gene, which alone are not sufficient to induce tumor formation (Ruivenkamp et al. 2002), the developmental phenotypes of dep-1 only manifest in sensitized genetic backgrounds. Therefore, C. elegans vulval development serves as a genetic model to identify the homologs of mammalian tumor suppressor genes and study their genetic interactions with conserved signaling pathways.

\section{Results}

A genetic screen for mutants with defects in $2^{\circ}$ cell fate specification

To identify new genes that regulate the $1^{\circ}$ versus $2^{\circ}$ vulval cell fate decision in parallel with lip-1 (Berset et al. 2001), we screened 30,000 haploid genomes in a lip-1(1f) background for mutants displaying defects in $2^{\circ}$ cell fate specification using morphological criteria (Fig. 1A). Descendants of $1^{\circ}$ vulval cells divide along the transverse (left-right) body axis, detach from the cuticula, and migrate inward (Katz et al. 1995). In this way, we isolated a loss-of-function mutation (zh34) in a previously uncharacterized gene that we named dep-1 (see below). Besides the zh34 mutation, we identified 15 mutations in other loci that cause a penetrant multivulva (Muv) phenotype but no apparent $2^{\circ}$ cell fate transformation in P5.p or P7.p descendants (T. Berset and A. Hajnal, unpubl.). Lineage analysis of dep-1(lf); lip-1(lf) double mutants and inspection of the vulval morphology in L4 larvae indicated that P5.p and P7.p descendants adopt a hybrid cell fate with $2^{\circ}$ and $1^{\circ}$ characteristics (a partial rotation of the cleavage planes in the last round of divisions followed by detachment from the cuticle), while dep-1(lf) or lip-1(lf) single mutants develop a wild-type vulva (Tables 1, 2; Fig. 1B-E). In addition, dep-1(lf); lip-1(lf)

Table 1. dep-1(lf); lip-1(lf) double mutants exhibit defects in the $2^{\circ}$ cell lineage

\begin{tabular}{lllllll}
\hline Genotype & P3.p & P4.p & P5.p & P6.p & P7.p & P8.p \\
\hline Wild type & S or SS & S S & LLTN & TTTT & NTLL & S S \\
lip-1(lf) & S or SS & S S & LLTN & TTTT & NTLL & S S \\
dep-1(lf) & S or SS & S S & LLTN & TTTT & NTLL & S S \\
dep-1(lf); lip-1(lf) & S & S OO & OOTN & TTTT & NTOL & S S \\
dep-1(lf); lip-1(lf) & SS & S S & LOTN & TTTT & NTOO & S S \\
dep-1(lf); lip-1(lf) & S & S S & OOON & TTTT & NTLL & S S \\
dep-1(lf); lip-1(lf) & SS & S S & LLON & TTTT & N?OL & S S \\
dep-1(lf); lip-1(lf) & SS & S S & OLTN & TTTT & NTLL & S S \\
dep-1(lf); lip-1(lf) & SS & S S & LLLN & TTTT & NTOL & S S \\
\hline
\end{tabular}

Vulval cell divisions were followed by observation under Nomarski optics as described (Hajnal et al. 1997). The last round of cell divisions was scored as follows: (L) division along the anterior posterior axis; $(\mathrm{T})$ division along the left-right axis; $(\mathrm{O})$ oblique cleavage plane; (N) refers to cells that did not divide during the third round of divisions. Cells that remained attached to the cuticle are underlined.

an these two animals, the detachment could not be unambiguously scored. The alleles used were dep-1(zh34), lip-1(zh15). 
Berset et al.

Figure 1. Identification and morphological characterization of dep-1. (A) Genetic screen to identify mutants with $2^{\circ}$ cell fate transformations. Wild-type vulva in an L4 larva $(B)$ and adult $(C)$. $(D)$ Vulva of a dep1(lf); lip-1(lf) L4 larva. Note that the P5.p and P7.p descendants have detached from the cuticula and moved inward (9). (E) Adult dep-1(lf); lip-1(lf) animal exhibiting a protrusion of vulval tissue due to the mixed $1^{\circ} / 2^{\circ}$ cell fate of P5.p and P7.p descendants. $(F, G)$ Overexpression of MPK-1 after the first round of VPC cell divisions causes a phenotype similar to the dep1(lf); lip-1(lf) L4 larva shown in D. (H) let60 ras(gf) L4 larva. P5.p and P7.p have adopted the $2^{\circ}$ fate, and their descendants remain attached to the cuticula, while some descendants of P4.p form an anterior pseudovulva (small arrow). (I) Adult let$60(g f)$ animal with a normal vulva in the center (large arrow) and an anterior pseudovulva (small arrow). A dep-1(lf); let$60(g f)$ L4 larva $(J)$ and adult $(K)$ animal exhibiting $2^{\circ}$ cell fate transformations in addition to the Muv phenotype. (L) A lin-12 notch(gf) L4 larva, in which all VPCs have adopted the $2^{\circ}$ fate. The orientations of the $2^{\circ}$ fates are indicated with arrows. $(M) \mathrm{A}$ dep-1(lf); lin-12(gf); lip-1(lf) triple mutant displaying multiple $2^{\circ}$ cell fate transformations. $(N)$ Percentage of L3 larvae displaying eg1-17::cfp expression in P5.px or P7.px cells. (O) Percentage of L3 larvae showing LET-23 expression in P5.p or P7.p descendants at the Pn.px and Pn.pxx stages. (P) LET-23 antibody staining of a lip-1(lf) and a dep-1(lf); lip-1(lf) mid-L3 larva at the Pn.pxx stage. MH27 staining of the adherens junctions in the animals is shown below. (Q) LIN-11::GFP expression from the syIs80 transgene (Gupta et al. 2003) in P5.p and P7.p descendants of wild-type and dep-1(1f); lip-1(lf) L4 larvae at the Pn.pxxx stage. Arrows point at the LIN-11 ::GFP expressing vulval cells. Bars, $10 \mu \mathrm{m}$.

animals exhibit a weak Muv phenotype due to ectopic induction of P3.p, P4.p, or P8.p (Table 2). The same phenotype can be observed if the EGFR/RAS/MAPK pathway is hyperactivated after the first round of vulval cell divisions has occurred by overexpressing MPK-1 under the control of a heat-shock-inducible promoter (Fig. 1F,G; Table 2; Lackner and Kim 1998). Thus, prolonged MAPK signaling causes similar $2^{\circ}$ cell fate defects as observed in dep-1(lf); lip-1(lf) double mutants, suggesting that dep-1 is necessary to keep the EGFR/RAS/ MAPK pathway inactive in the $2^{\circ}$ cell lineage even after vulval induction. To further test whether dep-1 inhibits $1^{\circ}$ cell fate specification in the presumptive $2^{\circ}$ cells, we removed dep-1 function in sensitized genetic backgrounds exhibiting elevated EGFR/RAS/MAPK signaling. A gain-of-function mutation in the let-60 ras gene or a reduction-of-function mutation in lin-15 causes a strong Muv phenotype, but loss of dep-1 function additionally results in a transformation of the $2^{\circ}$ cell fate in the P5.p and P7.p descendants similar to the defects observed in dep-1(lf); lip-1(lf) double mutants (Fig. 1H-K; Table 2).

Next, we used the egl-17::cfp reporter as a molecular marker for the $1^{\circ}$ cell fate (Burdine et al. 1998; Yoo et al. 2004). In a wild-type background, dep-1(lf) does not cause ectopic egl-17::cfp expression, but in a let-60(gf) background, dep-1(lf) increases the number of adjacent cells expressing egl-17::cfp (Fig. 1N). Loss of dep-1 function does not significantly enhance egl-17::cfp expression in a lip-1(lf) background, probably because lip-1(lf) single mutants already exhibit frequent ectopic egl17::cfp expression in P5.p and P7.p (Fig. 1N). Moreover, since egl-17::cfp expression does not always correlate with alterations in vulval morphology (Yoo et al. 2004), we tested LET-23 EGFR expression as another $1^{\circ}$ cell fate marker (Kaech et al. 1998). In wild-type L3 larvae, LET23 EGFR is strongly expressed in the $1^{\circ}$ descendants of P6.p but is down-regulated in the $2^{\circ}$ descendants of P5.p and P7.p. Ectopic LET-23 EGFR expression in $2^{\circ}$ cells is rarely observed in lip-1(lf) or dep-1(lf) single mutants, but in $51 \%$ of dep-1(lf); lip-1(lf) double mutants, LET-23 EGFR persists in P5.p and/or P7.p descendants (Fig. $1 \mathrm{O}, \mathrm{P})$.

Finally, we tested whether dep-1(If) affects the expression pattern of the $2^{\circ}$ cell fate marker lin-11::gfp (Gupta et al. 2003). In wild-type mid-L4 larvae at the Pn.pxxx 
Table 2. DEP-1 inhibits LET-23 EGFR signaling

\begin{tabular}{|c|c|c|c|}
\hline Genotype & Induced VPCs/animal $^{\mathrm{a}}$ & Vulval phenotype ${ }^{\mathrm{b}}$ & $n$ \\
\hline Wild type & 3.0 & wt & many \\
\hline $\operatorname{lip}-1(1 f)$ & 3.0 & wt & 50 \\
\hline dep-1(lf) & 3.0 & wt & 50 \\
\hline dep-1(lf); lip-1(lf) & 3.2 & $75 \% 2^{\circ} \Rightarrow 1^{\circ}, 19 \% \mathrm{Muv}$ & 101 \\
\hline lip-1(lf); gfp RNAic & 3.0 & wt & 20 \\
\hline lip-1(lf); dep-1 RNAic & 3.1 & $53 \% 2^{\circ} \Rightarrow 1^{\circ}, 10 \% \mathrm{Muv}$ & 92 \\
\hline dep-1(lf); lip-1(lf); zhEx90[dep-1(wt)] ${ }^{\mathrm{d}}$ & n.d. & $3 \% 2^{\circ} \Rightarrow 1^{\circ}$ & 33 \\
\hline dep-1(lf); lip-1(lf); zhEx113[dep-1::gfp] ${ }^{\mathrm{d}}$ & n.d. & $13 \% 2^{\circ} \Rightarrow 1^{\circ}$ & 23 \\
\hline let- $60(g f)$ & 4.2 & $2 \% 2^{\circ} \Rightarrow 1^{\circ}, 70 \% \mathrm{Muv}$ & 43 \\
\hline dep-1(lf);1et-60(gf) & 5.5 & $30 \% 2^{\circ} \Rightarrow 1^{\circ}, 100 \% \mathrm{Muv}$ & 41 \\
\hline $\operatorname{lin}-15$ (lf) & 6 & $49 \% 2^{\circ} \Rightarrow 1^{\circ}, 100 \% \mathrm{Muv}$ & 55 \\
\hline dep-1(lf); lin-15(lf) & 6 & $97 \% 2^{\circ} \Rightarrow 1^{\circ}, 100 \% \mathrm{Muv}$ & 57 \\
\hline hs::mpk-1 induced before VPC divisions $\mathrm{e}^{\mathrm{e}}$ & 5 & $100 \% 2^{\circ} \Rightarrow 1^{\circ}, 100 \% \mathrm{Muv}$ & 9 \\
\hline hs:: mpk-1 induced after VPC divisions ${ }^{\mathrm{e}}$ & 3.4 & $50 \% 2^{\circ} \Rightarrow 1^{\circ}, 20 \%$ Muv & 14 \\
\hline lip-1(lf) gonad ablated & 0 & $100 \%$ Vul & 18 \\
\hline dep-1(lf) gonad ablated & 0 & $100 \%$ Vul & 16 \\
\hline dep-1(lf); lip-1(lf) gonad ablated & 1.0 & $4 \% 2^{\circ} \Rightarrow 1^{\circ}, 92 \%$ Vul & 24 \\
\hline let-23(rf); gfp RNAic & 0.5 & $96 \%$ Vul & 25 \\
\hline let-23(rf); dep-1 RNAi ${ }^{\mathrm{c}}$ & $1.3^{\star}$ & $77 \%$ Vul & 31 \\
\hline lin-2(lf) & 0.3 & $100 \% \mathrm{Vul}$ & 28 \\
\hline dep-1(lf); lin-2(lf) & $2.3^{\star \star \star}$ & $44 \%$ Vul & 27 \\
\hline $\operatorname{lin}-7(1 f)$ & 0.2 & $100 \% \mathrm{Vul}$ & 24 \\
\hline dep-1(lf); lin-7(lf) & $2.5^{\star \star \star}$ & $20 \% \mathrm{Vul}$ & 18 \\
\hline $\operatorname{lin}-10(1 f)$ & 0.4 & $100 \% \mathrm{Vul}$ & 31 \\
\hline $\operatorname{lin}-10(1 f) ; \operatorname{dep}-1(1 f)$ & $1.3^{\star}$ & $64 \% \mathrm{Vul}$ & 22 \\
\hline sem-5(rf) & 0.9 & $76 \%$ Vul & 25 \\
\hline dep-1(lf); sem-5(rf) & 1.2 & $75 \%$ Vul & 24 \\
\hline bar-1(lf) & 2.5 & $30 \%$ Vul & 43 \\
\hline dep-1(lf); bar-1(lf) & 2.5 & $38 \%$ Vul & 40 \\
\hline
\end{tabular}

${ }^{a}$ Average number of VPCs per animal that have adopted a $1^{\circ}$ or $2^{\circ}$ vulval fate scored under Nomarski optics.

$\mathrm{b}\left(\% 2^{\circ} \Rightarrow 1^{\circ}\right)$ Fraction of animals, in which P5.p and/or P7.p have adopted a mixed $2^{\circ} / 1^{\circ}$ fate as shown in Figure 1D and Table $1 ;(\%$ Vul.) animals with fewer than three induced VPCs; $\left(\%\right.$ Muv) animals with more than three induced VPCs; $\left({ }^{\star \star \star}\right)$ a $p$ value $\leq 0.0001 ;\left({ }^{\star \star}\right)$ a $p$ value $\leq 0.001 ;\left(^{*}\right)$ a $p$ value $\leq 0.05$.

${ }^{c}$ RNAi experiments were done in the RNAi hypersensitive rrf-3(If) background.

'Young adults were analyzed for their vulva morphology under a dissecting microscope. Three independent $d e p-1$ (wt) lines and one dep-1::gfp line were tested for rescue.

${ }^{\mathrm{e}}$ Larvae at the indicated stages were heat-shocked for $30 \mathrm{~min}$ at $33^{\circ} \mathrm{C}$. See the Materials and Methods section for details on experimental procedures and alleles used.

stage, LIN-11::GFP is expressed in up to seven $2^{\circ}$ descendants of each P5.p and P7.p (Fig. 1Q; on average, 4.6 cells per $2^{\circ}$ lineage express LIN-11::GFP, $n=36$ ). Expression in the distal-most VulA cells P5.paax and P7.pppx is usually weak or not detectable (Gupta et al. 2003). In contrast, in dep-1(lf); lip-1(lf) double mutants, LIN-11::GFP expression is absent or strongly reduced in most $2^{\circ}$ cells (Fig. 1Q; on average, 1.8 cells per $2^{\circ}$ lineage weakly express LIN-11::GFP, $n=60$ ).

In summary, the morphological and molecular characterization of the cell fates in dep-1(lf); lip-1(lf) double mutants suggests that the dep-1(lf) phenotype is due to prolonged EGFR/RAS/MAPK signaling in P5.p and P7.p, which causes a transformation of the $2^{\circ}$ cell fate into a fate with mixed $1^{\circ}$ and $2^{\circ}$ character.

dep-1 acts downstream of or in parallel with LIN-12 NOTCH

To examine the genetic interaction between dep-1 and the lin-12 notch pathway, we tested whether dep-1(lf) affects $2^{\circ}$ fate specification in a lin-12 notch(gf) background, in which all six VPCs adopt the $2^{\circ}$ cell fate (Greenwald et al. 1983). In dep-1(lf); lin-12(gf) or lin12(gf); lip-1(lf) double mutants, all VPCs adopt the $2^{\circ}$ fate $(n=23$ and $n=22$, respectively), but $74 \%$ of $d e p$ 1(lf); lin-12(gf); lip-1(lf) triple mutants showed a transformation of the $2^{\circ}$ cell fate to a mixed $1^{\circ} / 2^{\circ}$ fate (Fig. $1 \mathrm{~L}, \mathrm{M} ; n=23$ ). Since lin-12(gf) animals have no AC, the somatic gonad in these animals produces no inductive LIN-3 EGF signal that could activate the LET-23 EGFR (Greenwald et al. 1983). However, gonad ablations demonstrated that vulval induction in dep-1(1f); lip-1(lf) animals can occur independently of the AC signal (Table 2). Thus, DEP-1 acts downstream of or in parallel with LIN$12 \mathrm{NOTCH}$ to inhibit $1^{\circ}$ fate specification.

\section{dep-1 encodes a receptor protein tyrosine phosphatase}

We identified F44G4.8 as the dep-1 locus by positional cloning (Fig. 2A; Materials and Methods). dep-1 encodes a protein of 1367 amino acids that exhibits strongest 
Berset et al.
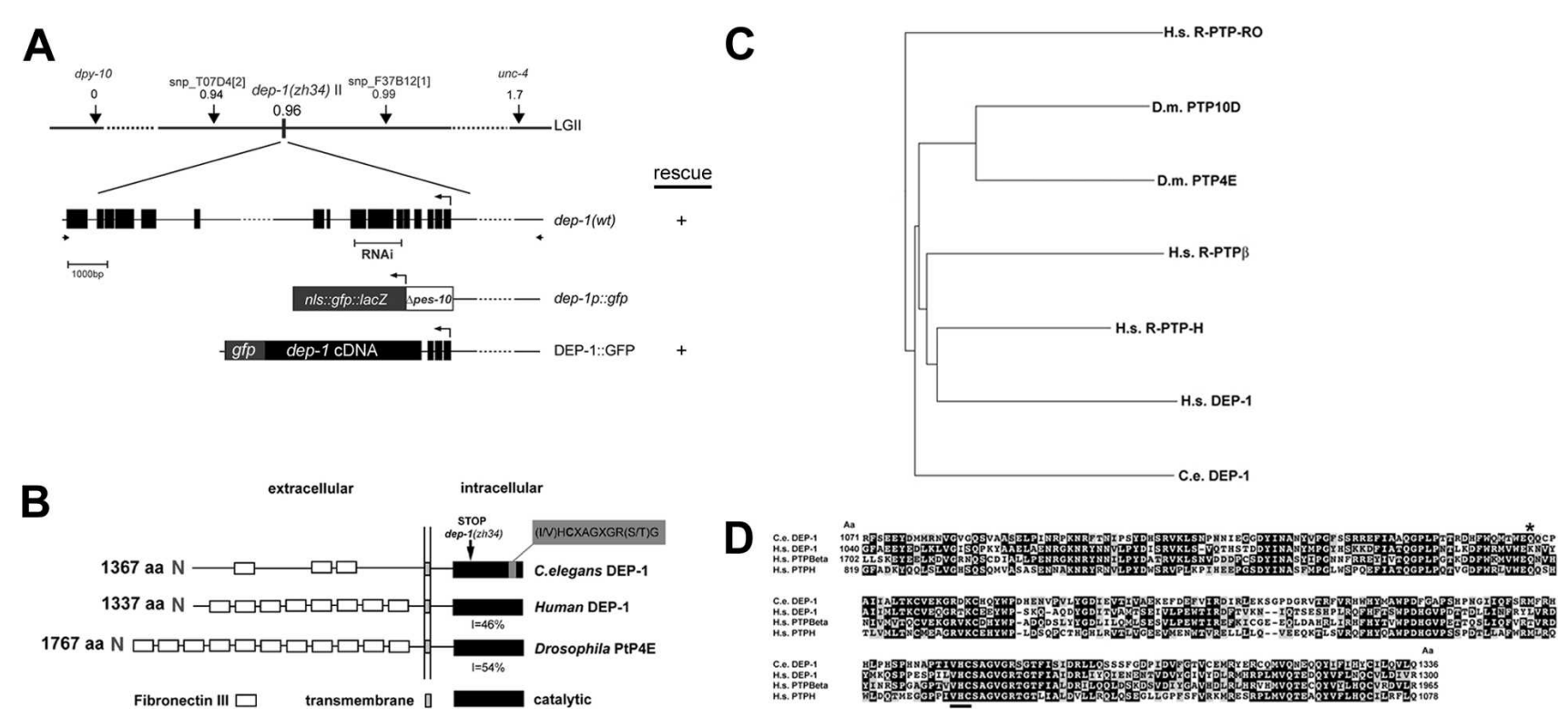

Figure 2. Positional cloning of dep-1. (A) Map position, intron-exon structure, and fragments used for rescue and RNAi experiments. (B) Domain structure of DEP-1 (F44G4.8) compared with human DEP-1 and Drosophila Ptp4E. Open boxes represent the fibronectinbinding III repeats and black boxes the catalytic phosphatase domain. "I" indicates the percent sequence identity between the catalytic domains. The location of the zh34 stop mutation and the catalytic center are highlighted. $(C)$ Dendogram showing the relationship between C. elegans (C.e.) DEP-1 (F44G4.8) and R-PTPs from Drosophila melanogaster (D.m.) and Homo sapiens (H.s.) calculated with the neighbor-joining method using the CLUSTAL X algorithm (Thompson et al. 1997). (D) Sequence alignment of the catalytic phosphatase domains of C. elegans DEP-1 with the catalytic domains of human class III R-PTPs. The asterisk indicates the position of the stop mutation in dep-1(zh34) animals, and the catalytic center containing the essential cysteine residue is underlined. GenBank accession numbers: (C.e.) DEP-1 CAA90125, (H.s.) DEP-1 Q12913, (H.s.) R-PTP-H NP002833, (H.s.) R-PTP $\beta$ P23467, (D.m.) PTP4E AAA76834, (D.m.) PTP10D P35992, (H.s.) R-PTP-RO AAH35960.

sequence similarity to the class III R-PTPs, which include the human Density-enhanced phosphatase-1 (DEP1) (Ostman et al. 1994), R-PTP-H (Marneros et al. 2001), and R-PTPBeta (Fig. 2B,C; Kaplan et al. 1990) as well as Drosophila Ptp4E and PTP10D (Yang et al. 1991). dep-1 encodes the only C. elegans phosphatase that contains the domain arrangement characteristic of the class III R-PTPs, as defined by the presence of a single intracellular catalytic tyrosine phosphatase domain, a transmembrane domain, and multiple extracellular fibronectin type III repeats (den Hertog 1999). Since mammalian DEP-1 is the founding member of this R-PTP family, we named the C. elegans F44G4.8 gene dep-1.

C. elegans dep-1(zh34) animals carry a stop mutation at position 1162, truncating the protein before the catalytic center of the phosphatase domain (Fig. 2B,D). Since this mutation is predicted to destroy the catalytic phosphatase activity, zh34 likely represents a loss- or strong reduction-of-function allele [dep-1(lf)]. Supporting these observations, RNAi against dep-1 in a lip-1(lf) background induces a penetrant dep-1 phenotype, and a genomic DNA fragment that spans the dep-1 locus rescues the vulval defects of dep-1(lf); lip-1(lf) animals (Fig. 2A; Table 2).

\section{DEP-1 inhibits LET-23 EGFR signaling}

Next, we tested whether dep-1 negatively regulates the activity of the LET-23 EGFR during vulval induction. dep-1(lf) suppresses the vulvaless (Vul) phenotype caused by lin-7, lin-2, or lin-10 mutations, which reduce but do not eliminate the activity of let-23 egfr (Kaech et al. 1998; Table 2). Furthermore, dep-1 RNAi suppresses the let-23 egfr(sy1) reduction-of-function mutation. (Since dep-1 maps within $<0.1$ map unit of let-23, we were unable to generate dep-1; let-23 double mutants.) In contrast, a sem-5 grb2(rf) mutation, which blocks signal transduction downstream of let-23 egfr (Clark et al. 1992), is not suppressed by dep-1(lf) (Table 2). Since wnt signaling promotes vulval cell fate specification in parallel to the EGFR/RAS/MAPK pathway, we examined the interaction of dep-1 with wht pathway mutants (Gleason et al. 2002). A mutation in the $\beta$-catenin bar-1 is not suppressed by dep-1(lf), indicating that DEP-1 does not act downstream of BAR-1. Furthermore, a mutation in the negative regulator of the wnt pathway pry-1 axin (Korswagen et al. 2002) causes a Muv phenotype but no ectopic egl-17::cfp expression (Fig. 1N).

Confirming the results of the epistasis analysis, we observed a physical interaction between DEP-1 and LET23 EGFR in GST pull-down experiments (Fig. 3). LET-23 EGFR from whole animal extracts specifically bound to the intracellular domain of DEP-1 carrying a substratetrapping mutation in the phosphatase domain (GST::DEP-1 $\mathrm{D}_{1241} \mathrm{~A}$ ) that allows the catalytically inactive enzyme to remain bound to its phosphorylated substrate (Palka et al. 2003). On the other hand, neither wild-type DEP-1 (GST::DEP-1wt) nor GST alone bound 


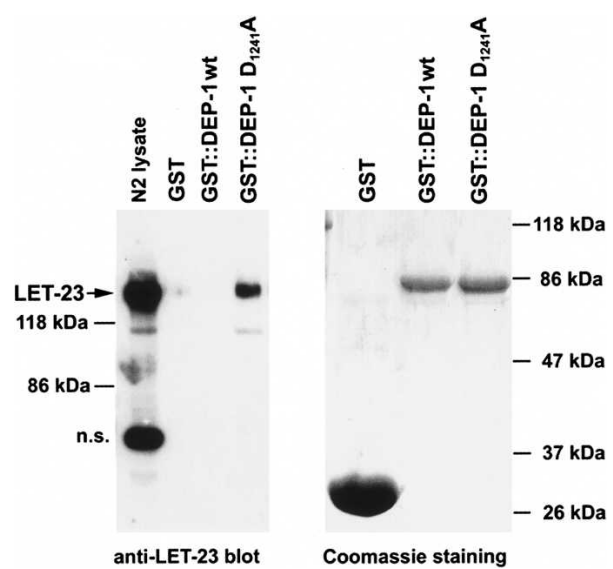

Figure 3. A substrate trapping mutant of DEP-1 binds LET-23 EGFR. (Left panel) Binding of LET-23 EGFR from N2 worm lysates to GST::DEP-1 fusion proteins detected on a Western blot with polyclonal LET-23 antibodies. Twenty percent of the amount of N2 lysate used in the binding reactions was loaded in the left-most lane. The band around $150 \mathrm{kDa}$ corresponds to full-length LET-23. "n.s." indicates a nonspecific cross-reacting band since a similar-sized band was detected in extracts from mammalian cells lacking LET-23 expression. The same amounts of recombinant proteins used for the binding reactions were loaded on a parallel gel stained with Coomassie blue shown in the right panel. For details on the assay conditions, see Materials and Methods.

to LET-23 EGFR. Taken together, these results suggest that DEP-1 inhibits inductive AC signaling by dephosphorylating LET-23 EGFR.

DEP-1::GFP is expressed in $2^{\circ}$ vulval cells independently of the lateral LIN-12 NOTCH signal

To investigate the dep-1 expression pattern, we generated a transcriptional dep-1p::gfp and a rescuing translational DEP-1::GFP reporter line (Fig. 2A; Table 2; see also Materials and Methods). Both reporters are expressed at the time of vulval induction at equal levels in P5.p, P6.p, and P7.p (Fig. 4A). After the first round of cell divisions, the translational DEP-1::GFP reporter is down-regulated in the $1^{\circ}$ lineage, but expression persists in the $2^{\circ}$ vulval cells until the L4 stage (Fig. 4B-D; Supplementary Fig. S1). DEP-1:: GFP expression is lower in P6.p than in P5.p or P7.p descendants in $82 \%$ of $\mathrm{L} 3$ and in $95 \%$ of L4 larvae ( $n=26$ and $n=21$, respectively). The DEP-1::GFP expression pattern is summarized in Figure 4O. A similar reduction of the expression in the $1^{\circ}$ lineage is observed with the transcriptional reporter, although the down-regulation in the $1^{\circ}$ lineage only becomes apparent at the Pn.pxx stage (Fig. 4G; Supplementay Fig. S2). dep-1p ::gfp expression is lower in P6.p than in P5.p or P7.p descendants in $80 \%$ of the L3 larvae $(n=78)$. In most cases (e.g., 17 out of 18 larvae at the Pn.px and Pn.pxx stages), DEP-1::GFP expression is low or absent in cells expressing high LET-23 EGFR levels and vice versa (Fig. 4E). Most of the DEP-1::GFP fusion protein is localized in intracellular punctae that partially colocalize with intracellular LET-23 EGFR (Fig. 4L,M).

Since the DEP-1::GFP expression pattern is very similar to that of a translational LIN-12::GFP reporter, we tested if dep-1 transcription is controlled by LIN-12 NOTCH (Levitan and Greenwald 1998; Shaye and Greenwald 2002). Although the dep-1p::gfp transcriptional reporter is expressed in ectopic $2^{\circ}$ cells of lin12(gf) mutants, no obvious up-regulation can be observed when compared with dep-1p::gfp levels in the $2^{\circ}$ VPCs of wild-type animals (Fig. 4G, $\mathrm{H}$; Supplementary Fig. S2). Unlike direct LIN-12 NOTCH target genes such as lip-1 (Berset et al. 2001), the P5.p and P7.p descendants continue to express dep-1p::gfp in a lin-12 notch(lf) background in $89 \%$ of the cases, although expression levels are slightly reduced in the P5.p and P7.p descendants $(n=37)$ (Fig. 4I; Supplementary Fig. S2). Furthermore, no
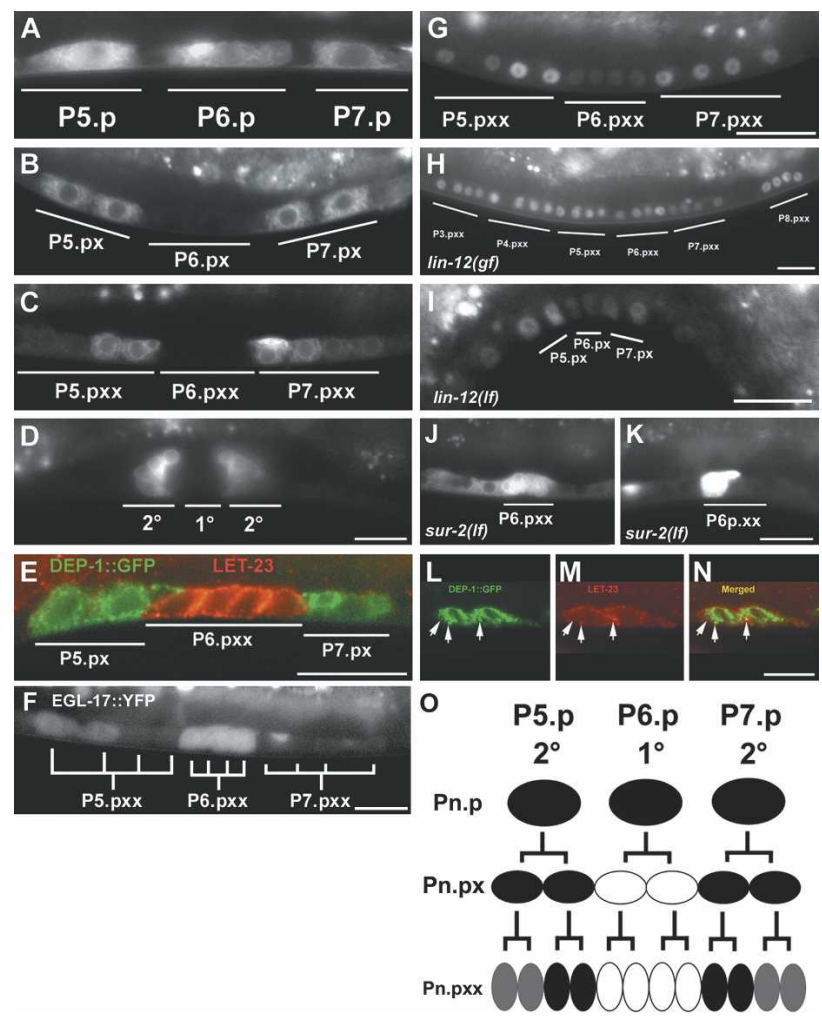

Figure 4. DEP-1::GFP expression pattern during vulval development. $(A-D)$ Expression pattern of the translational DEP$1::$ GFP reporter during vulval development. Note in $C$ the lower levels of DEP ::GFP in the two distal cells of the $2^{\circ}$ lineages at the Pn.pxx stage. (E) Mutually exclusive DEP-1::GFP and LET-23 antibody staining at the Pn.pxx stage. $(F)$ EGL$17::$ YFP expression at the Pn.pxx stage. Expression of the transcriptional dep-1p::gfp reporter in wild-type $(G), \operatorname{lin}-12(g f)(H)$, and lin-12(lf) (I) larvae at the Pn.pxx and Pn.px stages, respectively. Persisting DEP-1::GFP expression in all $(J)$ or half $(K)$ of the induced cells in sur-2(lf) mutants. Subcellular localization of DEP-1 ::GFP $(L)$ and LET-23 $(M)$ at the Pn.px stage. $(N)$ Merged image. Arrows point at intracellular punctae containing both DEP-1::GFP and LET-23. Bars: $N, 5 \mu \mathrm{m}$; otherwise, $10 \mu \mathrm{m}$. (O) Summary of the observed DEP-1::GFP expression pattern. 
Berset et al.

Table 3. DEP-1 acts in the $2^{\circ}$ cell lineage

\begin{tabular}{|c|c|c|c|c|c|}
\hline Row & P5.p & P6.p & P7.p & $\begin{array}{l}\text { Probable loss } \\
\text { of array in }{ }^{\mathrm{a}}\end{array}$ & $n$ \\
\hline 1 & $2^{\circ}$ & $1^{\circ}$ & $2^{\circ}$ & no loss & $486^{\mathrm{b}}$ \\
\hline & + & + & + & & \\
\hline 2 & $\begin{aligned} 2^{\circ} & \Rightarrow 1^{\circ} \\
& -\end{aligned}$ & $\begin{array}{l}1^{\circ} \\
-\end{array}$ & $\begin{aligned} 2^{\circ} & \Rightarrow 1^{\circ} \\
& -\end{aligned}$ & AB.p & 7 \\
\hline 3 & $\begin{array}{c}2^{\circ} \Rightarrow 1^{\circ} \\
-\end{array}$ & $\begin{array}{l}1^{\circ} \\
+\end{array}$ & $\begin{array}{l}2^{\circ} \\
-\end{array}$ & AB.pl \& >AB.pl ${ }^{c}$ & 2 \\
\hline 4 & $\begin{array}{c}2^{\circ} \Rightarrow 1^{\circ} \\
-\end{array}$ & $\begin{array}{l}1^{\circ} \\
+\end{array}$ & $\begin{aligned} 2^{\circ} & \Rightarrow 1^{\circ} \\
& -\end{aligned}$ & AB.pr & 1 \\
\hline 5 & $\begin{aligned} 2^{\circ} & \Rightarrow 1^{\circ} \\
& -\end{aligned}$ & $\begin{array}{l}1^{\circ} \\
+\end{array}$ & $\begin{array}{l}2^{\circ} \\
+\end{array}$ & AB.pl & 1 \\
\hline 6 & $\begin{array}{l}2^{\circ} \\
+\end{array}$ & $\begin{array}{l}1^{\circ} \\
-\end{array}$ & $\begin{array}{c}2^{\circ} \Rightarrow 1^{\circ} \\
-\end{array}$ & AB.pr & 1 \\
\hline 7 & $\begin{array}{l}2^{\circ} \\
+\end{array}$ & $\begin{array}{l}1^{\circ} \\
-\end{array}$ & $\begin{array}{l}2^{\circ} \\
+\end{array}$ & AB.pl, AB.pr \& >AB.pr ${ }^{\mathrm{d}}$ & 3 \\
\hline
\end{tabular}

${ }^{\mathrm{a} S e e}$ Materials and Methods for details on the identification and scoring of mosaic animals. (+) Presence of the rescuing array in the descendants of the respective $\mathrm{VPC} ;(-)$ absence of the array; $\left(2^{\circ} \Rightarrow 1^{\circ}\right)$ a transformation of the $2^{\circ}$ fate to a mixed $1^{\circ} / 2^{\circ}$ fate as described above (Figs. 1D, 5A; Table 1). The genotypes of P3.p, P4.p, and P8.p descendants could not be reliably scored because at the L4 stage they had fused with hyp7 and hence expressed GFP irrespective of the presence of the rescuing array.

${ }^{\mathrm{b}}$ One of the 486 animals exhibited the mutant phenotype despite the presence of the rescuing array in all vulval cells.

${ }_{\mathrm{c}, \mathrm{d}}$ In these two animals, the array had been lost in those parts of the AB.pl and AB.pr lineage, respectively, that gave rise to the $\mathrm{P}$ cells since both vulval cells and Pn.a-derived neurons lacked GFP expression.

cluster of CSL sites characteristic of the known LIN-12 $\mathrm{NOTCH}$ targets can be found in the regulatory region of dep-1 (Berset et al. 2001; Yoo et al. 2004). Thus, dep-1 is probably not a direct transcriptional target of the lateral DELTA/NOTCH signaling pathway.

\section{EGFR signaling coordinately down-regulates DEP-1 and LIN-12 NOTCH expression in the $1^{\circ}$ vulval cells}

In lin-12(gf) animals, which lack an AC and hence produce no inductive signal (Greenwald et al. 1983), dep$1 p:: g f p$ remains expressed in the P6.p descendants (Fig. $4 \mathrm{H})$, suggesting that EGFR/RAS/MAPK signaling downregulates dep- 1 expression in $1^{\circ}$ cells. Supporting this idea, we observed an asymmetric DEP-1::GFP expression pattern among the $2^{\circ}$ vulval cells that is complementary to the pattern of the EGFR/RAS/MAPK target egl-17 (Burdine et al. 1998; Cui and Han 2003). DEP$1::$ GFP levels are consistently higher in the proximal $2^{\circ}$ cells (P5.ppx and P7.pax) that are in direct contact with the $1^{\circ}$ descendants of P6.p that produce the lateral signal (Fig. 4C,O). Conversely, EGL-17::YFP expression is higher in the distal $2^{\circ}$ cells (P5.pax and P7.ppx) that probably receive less lateral signal and hence exhibit higher EGFR/RAS/MAPK pathway activity (Fig. 4F). To test whether EGFR/RAS/MAPK signaling represses DEP-1 transcription, we examined the DEP-1::GFP expression pattern in sur-2(lf) animals. sur-2 encodes a component of the mediator complex that acts downstream of the
EGFR/RAS/MAPK pathway to induce LIN-12 NOTCH down-regulation in $1^{\circ}$ cells and activate lateral signaling (Singh and Han 1995; Shaye and Greenwald 2002). In sur-2(lf) mutants, a $1^{\circ}$ vulval lineage is frequently induced in P6.p, but no $2^{\circ}$ cells are specified because P6.p produces no DSL ligands (Chen and Greenwald 2004). Similar to LIN-12::GFP, DEP-1 : GFP remains expressed in sur-2(lf) mutants in all or half of the cells in the $1^{\circ}$ lineage (Fig. 4J,K). Eighty percent of sur-2(lf) animals express DEP- $1:$ GFP in the $1^{\circ}$ lineage compared with $9 \%$ in a wild-type background, $n=54$ and 34 , respectively.

Thus, the AC signal simultaneously down-regulates DEP-1 and LIN-12 NOTCH expression in the $1^{\circ}$ vulval cells via the SUR-2 transcription factor.

\section{DEP-1 represses EGFR signaling in the $2^{\circ}$ cell lineage}

Although DEP-1::GFP is expressed at highest levels in the $2^{\circ}$ cells, the defects in $2^{\circ}$ cell fate specification could be an indirect consequence of a loss of dep-1 function in the $1^{\circ}$ cell lineage. To distinguish between a cell-autonomous function of dep- 1 in $2^{\circ}$ cells and a cell-non-autonomous function in the $1^{\circ}$ cells, we performed a dep- 1 mosaic analysis in a lip-1(lf) background. We identified 15 mosaic animals that fall into three classes (Table 3). (1) Seven animals were mutant for dep-1 in all vulval cells. In all of these cases, the P5.p and P7.p descendants exhibited a transformation of the $2^{\circ}$ cell fate to a mixed $1^{\circ} / 2^{\circ}$ cell fate as described above (Table 3, row 2). (2) Four
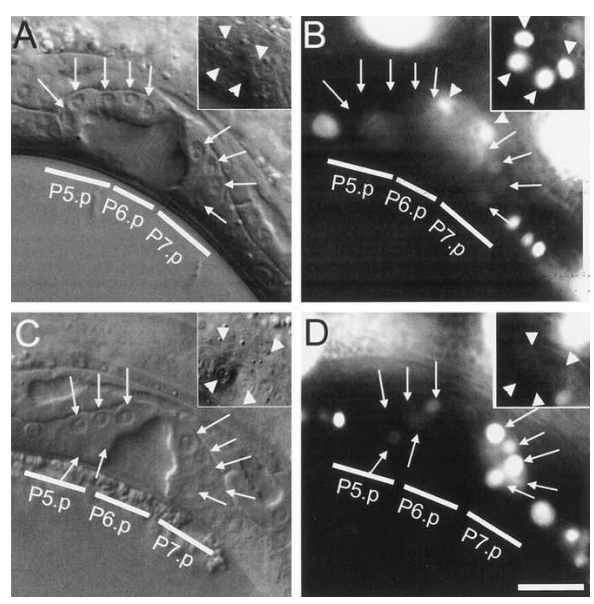

Figure 5. Cell-autonomous function of DEP-1 in the $2^{\circ}$ cell lineage. Two examples of the informative mosaic animals. Arrows indicate the position of the nuclei of P5.p and P7.p descendants; arrowheads point at the nuclei of P6.p descendants. $(A, C)$ Morphology of the P5.p and P7.p descendants at the L4 stage. $(B, D)$ Expression of the SUR-5::GFP cell lineage marker indicating presence of the rescuing dep-1(+) array zhEx 90 . The insets show the upper focal planes where four of the eight P6.p descendants are located. $(A, B)$ The animal from row 5 in Table 3. The descendants of P5.p lacked dep-1, while P6.p and P7.p descendants were wild type, resulting in a cell fate transformation of the P5.p descendants. $(C, D)$ One of the three animals from row 7 in Table 3 in which the descendants of P6.p lacked dep-1, while P5.p and P7.p descendants were wild type. P5.p and P7.p adopted a normal $2^{\circ}$ fate in this animal. Bar: $D, 10 \mu \mathrm{m}$. 
A
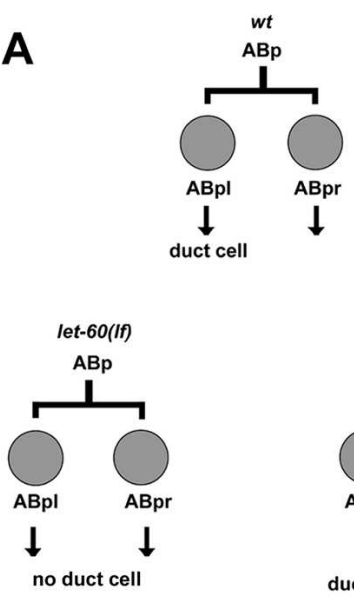

larval lethal

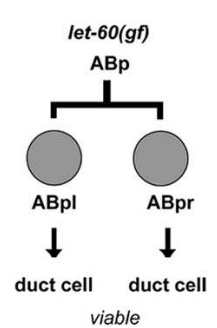

viable
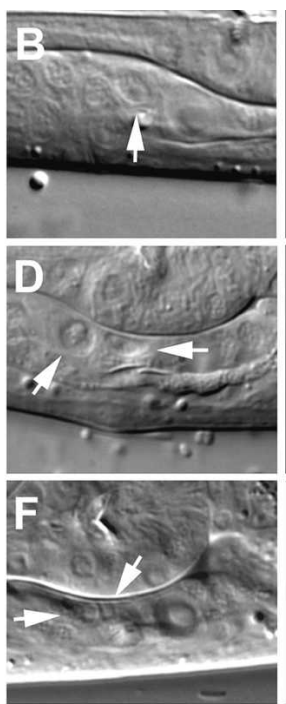

(
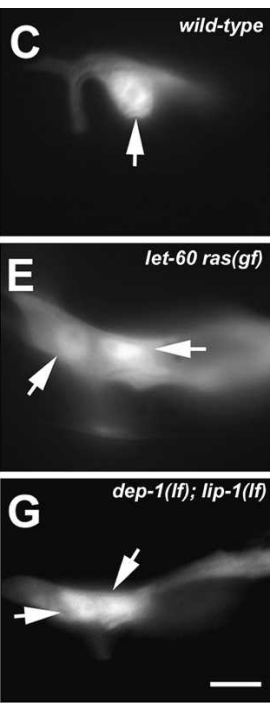

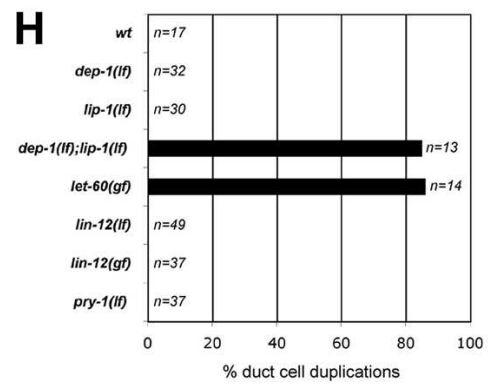

animals lacked dep-1 in P5.p and/or P7.p descendants, while the P6.p descendants contained the dep-1 transgene (Table 3, rows 3-5; Fig. 5A,B). In six out of eight cases, in which P5.p or P7.p was mutant for dep-1, we observed a $2^{\circ}$ cell fate transformation (including the animal from row 6 in Table 3). (3) Three animals expressed dep-1 in the P5.p and P7.p descendants but not in the P6.p descendants (Table 3, row 7; Fig. 5C,D). In these mosaic animals, P5.p and P7.p generated a normal $2^{\circ}$ cell lineage and a wild-type vulva developed. Taken together, the mosaic analysis points at a cell-autonomous function of $d e p-1$ in the $2^{\circ}$ cell lineage. These findings further support the idea that the $2^{\circ}$ cell fate transformation is caused by elevated LET-23 EGFR signaling in the $2^{\circ}$ cell lineage.

\section{DEP-1 regulates the binary cell fate choice} in the excretory system

To examine another example of a binary cell fate decision controlled by the EGFR/RAS/MAPK pathway, we asked whether DEP-1 regulates the specification of the duct cell fate in the excretory system (Fig. 6A; Yochem et al. 1997). During embryonic development, one descendant of each of the AB.pl and the AB.pr lineage has the potential to adopt the duct cell fate (Sulston et al. 1983). In wild-type animals, the AB.pl descendant differentiates into the duct cell, while the AB.pr descendant adopts an alternative cell fate, which presumably generates the G1

C. elegans DEP-1 inhibits EGFR signaling

Figure 6. DEP-1 controls duct cell specification. (A) Lineage relationship between the duct cell precursors and phenotypes caused by let-60 ras mutations (Yochem et al. 1997). Nomarski (B) and GFP fluorescence $(C)$ image of the duct cell in a wildtype L3 larva carrying the LIN-48::GFP reporter (Sewell et al. 2003). (D,E) let-60(gf) larva containing two duct cells. $(F, G)$ dep1(lf); lip-1(lf) animal exhibiting duct cell duplication. Arrows point at the nuclei of LIN-48::GFP-expressing cells. Bar, $5 \mu \mathrm{m}$. $(H)$ Quantification of the duct cell duplications. " $n$ " indicates the number of larvae scored for each genotype. cell that forms the excretory pore in the embryo and a neuroblast in the larva (Sulston et al. 1983). let-60 ras gain-of-function mutants develop two duct cells, whereas let-60 ras loss-of-function mutants contain no duct cell (Fig. 6A-E; Yochem et al. 1997). If the EGFR/ RAS/MAPK pathway is inactivated in the AB.pl lineage or the duct cell precursor is ablated, then the precursor cell from the AB.pr lineage generates the duct cell, indicating that the AB.pl-derived duct cell or its precursor normally inhibits the equipotent cell in the AB.pr lineage from producing a duct cell (Sulston et al. 1983; Yochem et al. 1997). dep-1(lf); lip-1(lf) double mutants frequently display duct cell duplications as shown by the ectopic expression of the lin-48::gfp marker (Fig. 6F-H; Sewell et al. 2003). In contrast, pry-1 axin(lf), bar-1(gf), and lin-12 notch(lf) mutants never have more than one duct cell, and lin-12(gf), glp-1 notch(gf), and bar-1(lf) mutants always contain a duct cell (Fig. 6H; Lambie and Kimble 1991). Thus, neither the wnt nor the lin-12 notch pathways control duct cell fate specification. Therefore, dep-1 inhibits EGFR/RAS/MAPK signaling in the duct cell precursors independently of the wnt and notch signals.

\section{Discussion}

\section{DEP-1 specifically inhibits LET-23 EGFR signaling}

We have identified the R-PTP DEP-1 in a forward genetic screen for genes that regulate the $1^{\circ}$ versus $2^{\circ}$ cell fate 


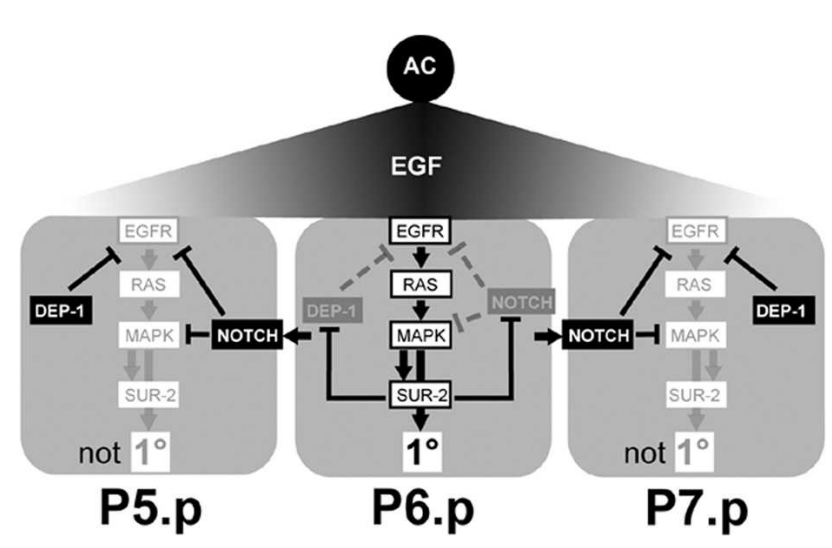

Figure 7. A model for DEP-1 function during vulval development. The inductive AC signal simultaneously down-regulates LIN-12 NOTCH and DEP-1 expression in P6.p via SUR-2, while LIN-12 and DEP-1 block the transduction of the inductive AC signal in P5.p and P7.p.

choice decision during C. elegans vulval development. Several lines of evidence indicate that DEP-1 specifically inhibits the transduction of the AC signal by dephosphorylating the EGFR homolog LET-23. First, LET-23 EGFR is the only RTK known to regulate $1^{\circ}$ vulval fate as well as duct cell specification. In both of these tissues, dep-1(lf) leads to the same phenotype as increased EGFR/RAS/MAPK signaling. Second, the genetic epistasis analysis indicates that DEP- 1 inhibits $1^{\circ}$ fate specification upstream of the adaptor protein SEM-5 GRB2. In addition, dep-1(lf) in combination with lip-1(lf) renders vulval induction partially independent from the AC signal, suggesting that in a dep-1(lf) background the ACindependent activity of LIN-3 EGF (Dutt et al. 2004) becomes sufficient to induce vulval differentiation. Third, protein interaction experiments show that the intracellular domain of DEP-1 is sufficient to bind to LET-23, as a substrate-trapping mutant of DEP-1 but not wild-type DEP-1 captures LET-23 EGFR from total animal lysates. This observation indicates that DEP- 1 specifically binds to phosphorylated LET-23 via its substrate-binding pocket in the phosphatase domain (Palka et al. 2003). Fourth, DEP-1 $\because:$ GFP and LET-23 EGFR are colocalized in intracellular punctae, suggesting that DEP-1 dephosphorylates LET-23 after the receptor has undergone ligand-induced endocytosis. Similarly, mammalian PTP$1 \mathrm{~B}$ interacts with internalized PDGFR and EGFR on the surface of the endoplasmic reticulum (Haj et al. 2002).

On the other hand, we did not observe a function of DEP-1 in developmental processes controlled by other RTKs. For example, dep-1(lf) suppresses neither the Dauer phenotype caused by a mutation in the daf-2 insulin receptor nor the EGL phenotype caused by an $r f$ mutation in the egl-15 fibroblast growth factor receptor (Kokel et al. 1998; data not shown). Also, the polarity reversal of the $2^{\circ}$ cell fate in P7.p caused by a mutation in the lin-17 frizzled receptor that acts together with the lin-18 Ryk/derailed family RTK is not affected by dep-1(If) (data not shown). On the other hand, RNAi analysis of 121 of the 165 predicted C. elegans protein phosphatase genes in a lip-1(lf) and dep-1(lf) background has identified no additional phosphatases that show a genetic interaction with lip-1 or dep-1 (U. Forster and A. Hajnal, unpubl.). Taken together, these observations point at a relatively high specificity of DEP-1 for LET-23 EGFR. This specificity may be achieved through a combination of the intrinsic substrate specificity of the phosphatase domain with a tightly regulated and dynamic expression pattern that maintains DEP-1 expression in a subset of cells and a restricted subcellular localization that allows DEP-1 to act only on internalized LET-23 EGFR.

\section{DEP-1 inhibits $1^{\circ}$ cell fate specification in parallel with the LIN-12 NOTCH pathway}

Lateral inhibition mediated by the NOTCH signaling pathway controls binary cell fate decisions during the development of most if not all animals (for review, see Lai 2004). In the developing vulva, LIN-12 NOTCH was found to inhibit $1^{\circ}$ cell fate specification in the future $2^{\circ}$ cells by inducing the transcription of a set of inhibitors of the inductive EGFR/RAS/MAPK pathway (Berset et al. 2001; Yoo et al. 2004). Although DEP-1::GFP expression is highest in $2^{\circ}$ vulval cells, dep-1 is not a direct LIN-12 NOTCH target gene. Rather, DEP-1 and LIN-12 NOTCH expression is simultaneously repressed in P6.p by the inductive EGFR/RAS/MAPK signaling pathway, which creates a positive feedback loop in the $1^{\circ}$ cell lineage (Fig. 7). Similar to LIN-12 NOTCH, the down-regulation of DEP-1 is mediated by the SUR-2 transcription factor (Shaye and Greenwald 2002). Since LIN-12 NOTCH signaling inactivates the EGFR/RAS/MAPK pathway in P5.p and P7.p, DEP-1 expression persists in the $2^{\circ}$ cells. Thus, DEP-1 inhibits LET-23 EGFR signaling in parallel with LIN-12 NOTCH to ensure a stable inhibition of the $1^{\circ}$ fate in P5.p and P7.p and their descendants. This conclusion is further supported by the finding that dep-1 controls the duct cell fate decision in the excretory system independently of the NOTCH pathway.

Why is such a complex regulatory network with multiple, genetically redundant inhibitors required for vulval pattern formation? Beginning in the L2 stage, the AC generates a gradient of LIN-3 EGF, which causes the activation of the EGFR/RAS/MAPK pathway in the proximal VPCs (P5.p, P6.p, and P7.p) (Yoo et al. 2004). Furthermore, a relay signal from the proximal VPCs propagates the AC signal to the distal VPCs (P3.p, P4.p, and P8.p) (Dutt et al. 2004). Even after vulval induction, the AC continues to express LIN-3 throughout the following vulval cell divisions. One explanation is therefore that the NOTCH-mediated lateral inhibition, which begins in the G1 phase of the VPC cell cycle only after the AC and relay signals have been received by the VPCs, does not irreversibly inhibit $1^{\circ}$ cell fate specification in P5.p and P7.p (Ambros 1999). Indeed, a $2^{\circ}$ cell can still be converted into a $1^{\circ}$ cell by increasing the MAPK signal until the G1 phase of the following cell cycle (Wang and Sternberg 1999). Thus, the repression of the EGFR/RAS/ MAPK pathway in the $2^{\circ}$ cells must be maintained for at 
least one more round of cell divisions. DEP-1 expression in the $2^{\circ}$ vulval cell lineage may be necessary to sustain the effect of lateral inhibition until the daughter cells of P5.p and P7.p have irreversibly adopted the $2^{\circ}$ fate.

Another possible answer lies in the developmental flexibility of vulval development. For example, if P6.p lacks LET-23 EGFR, then P5.p will adopt the $1^{\circ}$ instead of the $2^{\circ}$ fate it normally adopts, and its neighbors P4.p and P6.p will differentiate into $2^{\circ}$ cells instead of adopting the $3^{\circ}$ and $1^{\circ}$ fate, respectively (Simske and Kim 1995). Developmental flexibility may become even more important in higher organisms, where individual cells must be selected from much larger groups of precursor cells. It will therefore be interesting to see if DEP-1 performs a similar role during the development of higher organisms.

\section{C. elegans as a model to study tumor-suppressor gene function}

Our results establish $C$. elegans as a model to study the function of dep-1 during development, which may lead to an understanding of the molecular mechanism underlying the tumor suppressor activity of mammalian Dep1. Loss of C. elegans dep-1 function alone does not cause a visible developmental defect, but it shifts the balance in the uncommitted VPCs from the $2^{\circ}$ toward the $1^{\circ}$ cell fate. Similarly, mutations in human Dep-1/Scc1 alone are not sufficient to induce oncogenic transformation, but they increase the likelihood of tumor development in various epithelial tissues, especially in the intestinal mucosa (Ruivenkamp et al. 2002). In analogy to the function of C. elegans DEP-1, the defect leading to the formation of intestinal carcinomas may be a failure to restrict EGFR-stimulated cell proliferation in the epithelia as EGFR expression or activity is up-regulated in many human carcinomas (Holbro and Hynes 2004). At the base of intestinal crypts, stem cells can either proliferate or differentiate into migratory enterocytes that leave the base of the crypts. Possibly, loss of DEP-1 function shifts this balance, leading to an accumulation of proliferating undifferentiated cells that may further develop into tumor cells.

\section{Materials and methods}

\section{General C. elegans methods and strains}

C. elegans strains were cultured at $20^{\circ} \mathrm{C}$ as described (Brenner 1974). Wild type refers to C. elegans variety Bristol, strain N2. The mutations used are listed below. Unless noted otherwise, the mutations used have been described (Hodgkin 1997). Standard methods were used to construct double and triple mutants. Unless noted in the table legend, all experiments were conducted at $20^{\circ} \mathrm{C}$. dep-1(zh34) was cis-linked with unc-4(e120) or bli-1(e769) to construct the double mutants shown in Tables 1-3. The induction of VPCs was scored at the L4 larval stage using Nomarski optics as described (Berset et al. 2001). To ablate the gonad, the nuclei of the Z1-Z4 gonad precursor cells were ablated in early L1 larvae with a laser microbeam as de- scribed (Kimble 1981). The operated animals were allowed to develop until the L4 stage, when successfully ablated animals, in which neither gonad arm had developed and no residual gonadal cells survived, were identified under Nomarski optics.

The alleles used are LGI: lin-10(e1438), unc-13(e1091), unc101(sy108), sur-2(ku9), pry-1(mu38); LGII: dep-1(zh34) (this study), lin-7(e1413), unc-4(e120), dpy-10(e128), bli-1(e769), let23(sy1), rrf-3(pk1426) (Simmer et al. 2002). LGIII: unc119(e2498), dpy-19(e1259), lin-12(n137n7201f), unc-32(e189), lin-12(n137gf), daf-2(e1370). LGIV: lip-1(zh15) (Berset et al. 2001), let-60(n1046gf), lin-3(e1417), unc-5(e53), ark-1(sy247) (Hopper et al. 2000); LGX: sli-1(sy143) (Jongeward et al. 1995), gap-1(ga133) (Hajnal et al. 1997), lin-15(n309), sem-5(n2019), lin-2(n397), bar-1(ga80) (Eisenmann et al. 1998).

The transgenic arrays (transgene, cotransformation marker) were saIs14[1in-48::gfp, unc-119(+)] (Sewell et al. 2003), arIs92[egl-17p::cfp-lacZ,unc-4(+)] (Yoo et al. 2004), gaIs36[HSmpk-1(+),EF1alpha-D-mek(+)unc-30(+)] V (Lackner and Kim 1998), zhIs10[dep-1p-Apes::nls::gfp::1acZ, unc-119(+)] (this study), syIs80[lin-11::gfp, unc-119(+)] (Gupta et al. 2003), zhEx112[dep-1::gfp, unc-119(+)] (this study), zhEx113[dep$1:: g f p$, lin-48::gfp] (Johnson et al. 2001), zhEx90[F44G4.8, sur$5:: g f p]$ (this study).

\section{Positional cloning of dep-1}

Young adult lip-1(zh15) hermaphrodites were mutagenized with $50 \mathrm{mM}$ ethyl methanesulfonate for $4 \mathrm{~h}$ at room temperature, and the F2 generation was screened for mutants displaying $2^{\circ}$ cell fate defects. Approximately 30,000 haploid genomes were screened. dep-1(zh34); lip-1(zh15) mutants were backcrossed three times against Bristol N2, and chromosomal linkage of $z h 34$ to LGII was determined by bulk-segregant analysis as described (Wicks et al. 2001). Three factor mapping placed dep-1(zh34) between $d p y-10$ and unc-4, approximately at position 0.9. For high-resolution SNP mapping, unc4(e120) dep1(zh34); lip-1(zh15) and dpy-10(e128) dep-1(zh34); lip-1(zh15) animals were crossed with the polymorphic mapping strain $C$. elegans CB4856 (Wicks et al. 2001). Pvl nonUnc and Pvl nonDpy recombinants were isolated, and F3 clones homozygous for the recombinant chromosome were established. Informative SNPs were selected from the C. elegans Genome Sequencing Center Web site (http://genome.wustl.edu). SNP analysis defined a region between snp_F37B12 and snp_T07D4 (Fig. 2A). RNAi analysis (see below) of 54 of the predicted genes in this region in an $\operatorname{rrf}-3$ (pk1426); lip-1(zh15) background identified F44G4.8 as the candidate gene. Rescue experiments were performed as follows: 20.6-kb PCR products were amplified with TaKaRa LA Taq (TAKARA BIO INC) using the primers OTB57 (GGATTTTGAACCATTGGGTCG) and OTB44 (ATGAGCT ACCCGTGGAAACC) from the cosmid F44G4, pooled, and tested for integrity by restriction enzyme digestion. Thirty nanograms per microliter of purified PCR product was injected together with $50 \mathrm{ng} / \mathrm{\mu L}$ of pTG96 (sur-5::gfp) as a transformation marker into wild-type animals, and three independent transgenic lines were crossed to dep-1(zh34); lip-1(zh15) mutants to assay for rescue.

\section{GFP reporter constructs}

For the dep-1p::gfp transcriptional reporter, a 6.1-kb fragment from the 5'-region of $d e p-1$ was PCR-amplified from wild-type genomic DNA with the primers OTB77 /GCATGCGGAAAGT GATCGAATTGACCG) and OTB76 (GCATGCGTAGTTTT TCCGCAACTCGTG), digested with SphI, and cloned into pTB11. pTB11 contains a 370-bp BamHI fragment with a $\Delta$ pes- 
10 minimal promoter isolated from pPD95.21 and inserted into the BamHI site of the nls::gfp::1acZ reporter plasmid pPD96.04. (All pPD plasmids are gifts of A. Fire, Stanford, CA.) The translational dep-1::gfp reporter was constructed as follows: A 5.6-kb genomic PCR fragment that includes $4.5 \mathrm{~kb}$ of the dep-1 upstream region was amplified from wild-type DNA with the primers OTB94 (GTCGACGGATTTTGAACCATTGGGTCG) and OTB70 (GGTCTACTACTCATTCCGTC), digested with SalI and BamHI and cloned into pPD95.75. A second fragment of $3.7 \mathrm{~kb}$ was amplified from $\mathrm{dep}-1 \mathrm{cDNA}$ with the primers OTB93 (TTTGCCATCAAGAAGGATTCC) and OTB92 (GGATCCC GAAATCCCGATTCGACAATCAT), digested with BamHI, and cloned in frame to $g f p$.

\section{Transgenic animals}

Transgenic animals were generated either by microinjection of DNA or by microparticle bombardment as described (Mello et al. 1991; Praitis et al. 2001). Where indicated, extrachromosomal arrays were integrated into the genome by $\gamma$-irradiation of L4 larvae. Integrated arrays were backcrossed at least five times before further analysis.

\section{GST pull-down experiments}

A cDNA fragment encoding the intracellular domain of DEP-1 (amino acids 925-1367) was cloned into the BamHI site of the Escherichia coli expression vector pGEX-2TK (Pharmacia). The $\mathrm{D}_{1241}$-to-A mutation was introduced by site-directed mutagenesis using the Quick-Change Kit (Stratagene). Recombinant proteins were affinity-purified on glutathione Sepharose beads according to the manufacturer's protocol (Pharmacia), except that protein expression was induced in $\mathrm{BL} 21$ bacteria at $25^{\circ} \mathrm{C}$, and fusion proteins were extracted in the presence of $0.1 \%$ Triton X-100 and $450 \mathrm{mM} \mathrm{NaCl}$. Approximately $1 \mu \mathrm{g}$ of each DEP-1 fusion protein and $10 \mu \mathrm{g}$ of GST as negative control were used in each binding reaction. To prepare N2 worm extracts, mixedstage cultures were washed three times with PBS, resuspended in lysis buffer ( $25 \mathrm{mM}$ Tris at $\mathrm{pH} 7.5,150 \mathrm{mM} \mathrm{NaCl}, 0.5 \%$ Triton X-100, $10 \mathrm{mM}$ EDTA, 1× protease inhibitor cocktail; Roche), homogenized with a douncer, and centrifuged for 15 min at $4^{\circ} \mathrm{C}$ and $10,000 \mathrm{~g}$ to remove insoluble components. About $100 \mu \mathrm{g}$ of total protein extract was used in each reaction. Binding was performed at room temperature for $2 \mathrm{~h}$, the Sepharose beads were washed three times with lysis buffer, and bound proteins were eluted by boiling the beads for $5 \mathrm{~min}$ in SDS gel-loading buffer. LET-23 was detected on Western blots of $10 \%$ acrylamide gels with polyclonal affinity-purified LET-23 antibody (Kaech et al. 1998). Similar results were obtained using a monoclonal antibody raised against the same LET-23 epitope (data not shown).

\section{Antibody staining and GFP expression studies}

LET-23 antibody staining using a polyclonal antibody against the LET-23 C terminus was performed as described in Kaech et al. (1998). GFP and CFP expression was observed under fluorescent light illumination with a Leica DMRA microscope equipped with a cooled CCD camera (Hamamatsu ORCA-ER) controlled by the Openlab 3.0 software package (Improvision). To score GFP expression in the Pn.p cells, animals were mounted on 3\% agarose pads in $\mathrm{M} 9$ solution containing $15 \mathrm{mM} \mathrm{NaN}_{3}$. Larvae were first inspected using Nomarski optics to identify the position of the Pn.p cells or their descendants, and GFP expression was then scored under fluorescent light illumination using the same exposure settings for a particular transgene in all different genetic backgrounds.

\section{RNAi interference}

RNAi was performed by feeding worms with dsRNA-producing E. coli as described (Kamath et al. 2001) with the following modifications: Five to $10 \mathrm{~L} 1$ larvae were placed on the RNAi plates, and the P0 and F1 generations were inspected for vulval phenotypes. Three millimolar IPTG was added to the agar to induce the expression of dsRNA.

\section{Mosaic analysis}

Mosaic analysis was done as described (Hajnal et al. 1997) except that sur-5::gfp was used as a cell lineage marker instead of ncl-1. The sur-5::gfp marker has the advantage over ncl-1 that the genotype of the vulval cells can be reliably scored under fluorescence light illumination (Yochem et al. 1997). L4 larvae of the genotype dep-1(zh34) unc-4(e120); lip-1(zh15); zhEx90.3[F44G4.8, sur-5::gfp] were anesthetized with $10 \mathrm{mM}$ $\mathrm{NaN}_{3}$ and inspected under Nomrski optics in batches of 20-30 animals. First, animals exhibiting a mutant vulval phenotype were scored for GFP expression in the following cells to infer the most likely site of loss of the rescuing array: intestinal cells, anchor cell, body wall muscles in the head and distal tip cells (all EMS derived), ASKR, ADLR head neurons, excretory cell, Pn.a-derived motor neurons and the vulval cells (all from the AB.p lineage), and ASKL and MI (AB.a-derived head neurons). Finally, animals exhibiting a wild-type vulval phenotype were screened for a loss of the rescuing array in the $1^{\circ}$ or $2^{\circ}$ vulval cells to identify those mosaics that permit wild-type vulval development (Table 3, row 7).

\section{Acknowledgments}

We thank all lab members, Fritz Müller, Ernst Hafen, Peter Gallant, and Hugo Stocker for critical review of the manuscript; Ivo Riman for assistance with the egl-17::yfp reporter; A. Fire for GFP reporter plasmids; Helen Chamberlin for the lin-48::gfp reporter; Stuart Kim for LET-23 antibodies; Julie Ahringer for RNAi clones; Yuji Kohara for dep-1 cDNA; Alan Coulson for cosmids; and the Caenorhabditis elegans Genetics Center for some of the strains used. This work was supported by grants from the Swiss Cancer League and SNF to A.H. and the Kanton Zürich.

\section{References}

Alonso, A., Sasin, J., Bottini, N., Friedberg, I., Osterman, A., Godzik, A., Hunter, T., Dixon, J., and Mustelin, T. 2004. Protein tyrosine phosphatases in the human genome. Cell 117: 699-711.

Ambros, V. 1999. Cell cycle-dependent sequencing of cell fate decisions in Caenorhabditis elegans vulva precursor cells. Development 126: 1947-1956.

Berset, T., Hoier, E.F., Battu, G., Canevascini, S., and Hajnal, A. 2001. Notch inhibition of RAS signaling through MAP kinase phosphatase LIP-1 during C. elegans vulval development. Science 291: 1055-1058.

Bhaduri, A. and Sowdhamini, R. 2003. A genome-wide survey of human tyrosine phosphatases. Protein Eng. 16: 881-888.

Blanchetot, C., Chagnon, M., Dube, N., Halle, M., and Tremblay, M.L. 2005. Substrate-trapping techniques in the identification of cellular PTP targets. Methods 35: 44-53. 
Brenner, S. 1974. The genetics of Caenorhabditis elegans. Genetics 77: 71-94.

Burdine, R.D., Branda, C.S., and Stern, M.J. 1998. EGL-17(FGF) expression coordinates the attraction of the migrating sex myoblasts with vulval induction in C. elegans. Development 125: 1083-1093.

Chen, N. and Greenwald, I. 2004. The lateral signal for LIN-12/ Notch in C. elegans vulval development comprises redundant secreted and transmembrane DSL proteins. Dev. Cell 6: $183-192$.

Clark, S.G., Stern, M.J., and Horvitz, H.R. 1992. C. elegans cellsignalling gene sem-5 encodes a protein with $\mathrm{SH} 2$ and $\mathrm{SH} 3$ domains. Nature 356: 340-344.

Cui, M. and Han, M. 2003. Cis regulatory requirements for vulval cell-specific expression of the Caenorhabditis elegans fibroblast growth factor gene egl-17. Dev. Biol. 257: 104-116.

den Hertog, J. 1999. Protein-tyrosine phosphatases in development. Mech. Dev. 85: 3-14.

Dutt, A., Canevascini, S., Froehli-Hoier, E., and Hajnal, A. 2004. EGF signal propagation during C. elegans vulval development mediated by ROM-1 rhomboid. PLOS Biol. 2: E334.

Eisenmann, D.M., Maloof, J.N., Simske, J.S., Kenyon, C., and Kim, S.K. 1998. The $\beta$-catenin homolog BAR-1 and LET-60 Ras coordinately regulate the Hox gene lin-39 during Caenorhabditis elegans vulval development. Development 125: 3667-3680.

Elchebly, M., Payette, P., Michaliszyn, E., Cromlish, W., Collins, S., Loy, A.L., Normandin, D., Cheng, A., Himms-Hagen, J., Chan, C.C., et al. 1999. Increased insulin sensitivity and obesity resistance in mice lacking the protein tyrosine phosphatase-1B gene. Science 283: 1544-1548.

Gleason, J.E., Korswagen, H.C., and Eisenmann, D.M. 2002. Activation of Wnt signaling bypasses the requirement for RTK/ Ras signaling during C. elegans vulval induction. Genes \& Dev. 16: 1281-1290.

Grazia Lampugnani, M., Zanetti, A., Corada, M., Takahashi, T., Balconi, G., Breviario, F., Orsenigo, F., Cattelino, A., Kemler, R., Daniel, T.O., et al. 2003. Contact inhibition of VEGFinduced proliferation requires vascular endothelial cadherin, $\beta$-catenin, and the phosphatase DEP-1/CD148. I. Cell Biol. 161: 793-804.

Greenwald, I.S., Sternberg, P.W., and Horvitz, H.R. 1983. The lin-12 locus specifies cell fates in Caenorhabditis elegans. Cell 34: 435-444.

Gupta, B.P., Wang, M., and Sternberg, P.W. 2003. The C. elegans LIM homeobox gene lin-11 specifies multiple cell fates during vulval development. Development 130: 2589-2601.

Haj, F.G., Verveer, P.J., Squire, A., Neel, B.G., and Bastiaens, P.I. 2002. Imaging sites of receptor dephosphorylation by PTP1B on the surface of the endoplasmic reticulum. Science 295: 1708-1711.

Haj, F.G., Markova, B., Klaman, L.D., Bohmer, F.D., and Neel, B.G. 2003. Regulation of receptor tyrosine kinase signaling by protein tyrosine phosphatase-1B. J. Biol. Chem. 278: 739744.

Hajnal, A., Whitfield, C.W., and Kim, S.K. 1997. Inhibition of Caenorhabditis elegans vulval induction by gap-1 and by let-23 receptor tyrosine kinase. Genes \& Dev. 11:27152728.

Harroch, S., Palmeri, M., Rosenbluth, J., Custer, A., Okigaki, M., Shrager, P., Blum, M., Buxbaum, J.D., and Schlessinger, J. 2000. No obvious abnormality in mice deficient in receptor protein tyrosine phosphatase $\beta$. Mol. Cell. Biol. 20: 77067715.

Hodgkin, J. 1997. Appendix I: Genetics. In C. elegans II. Cold
Spring Harbor Monograph Series, 33 (eds. D.L. Riddle et al.), pp 881-1048. Cold Spring Harbor Laboratory Press, Cold Spring Harbor, NY.

Holbro, T. and Hynes, N.E. 2004. ErbB receptors: Directing key signaling networks throughout life. Annu. Rev. Pharmacol. Toxicol. 44: 195-217.

Hopper, N.A., Lee, J., and Sternberg, P.W. 2000. ARK-1 inhibits EGFR signaling in C. elegans. Mol. Cell 6: 65-75.

Jandt, E., Denner, K., Kovalenko, M., Ostman, A., and Bohmer, F.D. 2003. The protein-tyrosine phosphatase DEP-1 modulates growth factor-stimulated cell migration and cell-matrix adhesion. Oncogene 22: 4175-4185.

Johnson, A.D., Fitzsimmons, D., Hagman, J., and Chamberlin, H.M. 2001. EGL-38 Pax regulates the ovo-related gene lin-48 during Caenorhabditis elegans organ development. Development 128: 2857-2865.

Jongeward, G.D., Clandinin, T.R., and Sternberg, P.W. 1995. sli-1, a negative regulator of let-23-mediated signaling in $C$. elegans. Genetics 139: 1553-1566.

Kaech, S.M., Whitfield, C.W., and Kim, S.K. 1998. The LIN-2/ LIN-7/LIN-10 complex mediates basolateral membrane localization of the C. elegans EGF receptor LET-23 in vulval epithelial cells. Cell 94: 761-771.

Kamath, R.S., Martinez-Campos, M., Zipperlen, P., Fraser, A.G., and Ahringer, J. 2001. Effectiveness of specific RNA-mediated interference through ingested double-stranded RNA in Caenorhabditis elegans. Genome Biol. 2: RESEARCH0002.

Kaplan, R., Morse, B., Huebner, K., Croce, C., Howk, R., Ravera, M., Ricca, G., Jaye, M., and Schlessinger, J. 1990. Cloning of three human tyrosine phosphatases reveals a multigene family of receptor-linked protein-tyrosine-phosphatases expressed in brain. Proc. Natl. Acad. Sci. 87: 7000-7004.

Karim, F.D. and Rubin, G.M. 1999. PTP-ER, a novel tyrosine phosphatase, functions downstream of Ras1 to downregulate MAP kinase during Drosophila eye development. Mol. Cell 3: 741-750.

Katz, W.S., Hill, R.J., Clandinin, T.R., and Sternberg, P.W. 1995. Different levels of the C. elegans growth factor LIN-3 promote distinct vulval precursor fates. Cell 82: 297-307.

Keane, M.M., Lowrey, G.A., Ettenberg, S.A., Dayton, M.A., and Lipkowitz, S. 1996. The protein tyrosine phosphatase DEP-1 is induced during differentiation and inhibits growth of breast cancer cells. Cancer Res. 56: 4236-4243.

Kimble, J. 1981. Alterations in cell lineage following laser ablation of cells in the somatic gonad of Caenorhabditis elegans. Dev. Biol. 87: 286-300.

Kokel, M., Borland, C.Z., DeLong, L., Horvitz, H.R., and Stern, M.J. 1998. clr-1 encodes a receptor tyrosine phosphatase that negatively regulates an FGF receptor signaling pathway in Caenorhabditis elegans. Genes \& Dev. 12: 1425-1437.

Korswagen, H.C., Coudreuse, D.Y., Betist, M.C., van de Water, S., Zivkovic, D., and Clevers, H.C. 2002. The Axin-like protein PRY-1 is a negative regulator of a canonical Wnt pathway in C. elegans. Genes \& Dev. 16: 1291-1302.

Lackner, M.R. and Kim, S.K. 1998. Genetic analysis of the Caenorhabditis elegans MAP kinase gene mpk-1. Genetics 150: $103-117$.

Lai, E.C. 2004. Notch signaling: Control of cell communication and cell fate. Development 131: 965-973.

Lambie, E.J. and Kimble, J. 1991. Two homologous regulatory genes, lin-12 and glp-1, have overlapping functions. Development 112: 231-240.

Lee, J., Jongeward, G.D., and Sternberg, P.W. 1994. unc-101, a gene required for many aspects of Caenorhabditis elegans development and behavior, encodes a clathrin-associated protein. Genes \& Dev. 8: 60-73. 
Levitan, D. and Greenwald, I. 1998. LIN-12 protein expression and localization during vulval development in C. elegans. Development 125: 3101-3109.

Marneros, A.G., Mehenni, H., Reichenberger, E., Antonarakis, S.E., Krieg, T., and Olsen, B.R. 2001. Gene for the human transmembrane-type protein tyrosine phosphatase $\mathrm{H}$ (PTPRH): Genomic structure, fine-mapping and its exclusion as a candidate for Peutz-Jeghers syndrome. Cytogenet. Cell Genet. 92: 213-216.

Mello, C.C., Kramer, J.M., Stinchcomb, D., and Ambros, V. 1991. Efficient gene transfer in C. elegans: Extrachromosomal maintenance and integration of transforming sequences. EMBO I. 10: 3959-3970.

Ostman, A., Yang, Q., and Tonks, N.K. 1994. Expression of DEP-1, a receptor-like protein-tyrosine-phosphatase, is enhanced with increasing cell density. Proc. Natl. Acad. Sci. 91: 9680-9684.

Palka, H.L., Park, M., and Tonks, N.K. 2003. Hepatocyte growth factor receptor tyrosine kinase met is a substrate of the receptor protein-tyrosine phosphatase DEP-1. I. Biol. Chem. 278: 5728-5735.

Praitis, V., Casey, E., Collar, D., and Austin, J. 2001. Creation of low-copy integrated transgenic lines in Caenorhabditis elegans. Genetics 157: 1217-1226.

Ruivenkamp, C.A., van Wezel, T., Zanon, C., Stassen, A.P., Vlcek, C., Csikos, T., Klous, A.M., Tripodis, N., Perrakis, A., Boerrigter, L., et al. 2002. Ptpri is a candidate for the mouse colon-cancer susceptibility locus Scc1 and is frequently deleted in human cancers. Nat. Genet. 31: 295-300.

Schlessinger, J. 2000. Cell signaling by receptor tyrosine kinases. Cell 103: 211-225.

Sewell, S.T., Zhang, G., Uttam, A., and Chamberlin, H.M. 2003. Developmental patterning in the Caenorhabditis elegans hindgut. Dev. Biol. 262: 88-93.

Shaye, D.D. and Greenwald, I. 2002. Endocytosis-mediated downregulation of LIN-12/Notch upon Ras activation in Caenorhabditis elegans. Nature 420: 686-690.

Simmer, F., Tijsterman, M., Parrish, S., Koushika, S.P., Nonet, M.L., Fire, A., Ahringer, J., and Plasterk, R.H. 2002. Loss of the putative RNA-directed RNA polymerase RRF-3 makes C. elegans hypersensitive to RNAi. Curr. Biol. 12: 13171319.

Simske, J.S. and Kim, S.K. 1995. Sequential signalling during Caenorhabditis elegans vulval induction. Nature 375: 142146.

Singh, N. and Han, M. 1995. sur-2, a novel gene, functions late in the let-60 ras-mediated signaling pathway during Caenorhabditis elegans vulval induction. Genes \& Dev. 9: 2251-2265.

Sulston, J.E., Schierenberg, E., White, J.G., and Thomson, J.N. 1983. The embryonic cell lineage of the nematode Caenorhabditis elegans. Dev. Biol. 100: 64-119.

Sundaram, M.V. 2004. Vulval development: The battle between Ras and Notch. Curr. Biol. 14: R311-R313.

Thompson, J.D., Gibson, T.J., Plewniak, F., Jeanmougin, F., and Higgins, D.G. 1997. The CLUSTAL_X windows interface: Flexible strategies for multiple sequence alignment aided by quality analysis tools. Nucleic Acids Res. 25: 4876-4882.

Trapasso, F., Iuliano, R., Boccia, A., Stella, A., Visconti, R., Bruni, P., Baldassarre, G., Santoro, M., Viglietto, G., and Fusco, A. 2000. Rat protein tyrosine phosphatase $\eta$ suppresses the neoplastic phenotype of retrovirally transformed thyroid cells through the stabilization of p27(Kip1). Mol. Cell. Biol. 20: 9236-9246.
Wang, M. and Sternberg, P.W. 1999. Competence and commitment of Caenorhabditis elegans vulval precursor cells. Dev. Biol. 212: 12-24.

Wicks, S.R., Yeh, R.T., Gish, W.R., Waterston, R.H., and Plasterk, R.H. 2001. Rapid gene mapping in Caenorhabditis elegans using a high density polymorphism map. Nat. Genet. 28: 160-164.

Yang, X.H., Seow, K.T., Bahri, S.M., Oon, S.H., and Chia, W. 1991. Two Drosophila receptor-like tyrosine phosphatase genes are expressed in a subset of developing axons and pioneer neurons in the embryonic CNS. Cell 67: 661-673.

Yochem, J., Sundaram, M., and Han, M. 1997. Ras is required for a limited number of cell fates and not for general proliferation in Caenorhabditis elegans. Mol. Cell. Biol. 17: 27162722.

Yoo, A.S., Bais, C., and Greenwald, I. 2004. Crosstalk between the EGFR and LIN-12/Notch pathways in C. elegans vulval development. Science 303: 663-666.

Yoon, C.H., Lee, J., Jongeward, G.D., and Sternberg, P.W. 1995. Similarity of sli-1, a regulator of vulval development in C. elegans, to the mammalian proto-oncogene c-cbl. Science 269: 1102-1105. 


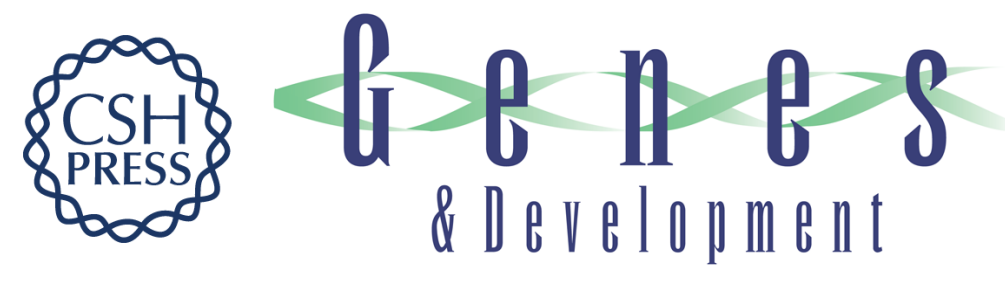

\section{The $C$. elegans homolog of the mammalian tumor suppressor Dep-1/Scc1 inhibits EGFR signaling to regulate binary cell fate decisions}

Thomas A. Berset, Erika Fröhli Hoier and Alex Hajnal

Genes Dev. 2005, 19:

Access the most recent version at doi:10.1101/gad.333505

Supplemental Material

References License

Email Alerting Service
http://genesdev.cshlp.org/content/suppl/2005/05/18/gad.333505.DC1

This article cites 62 articles, 32 of which can be accessed free at: http://genesdev.cshlp.org/content/19/11/1328.full.html\#ref-list-1

Receive free email alerts when new articles cite this article - sign up in the box at the top right corner of the article or click here.

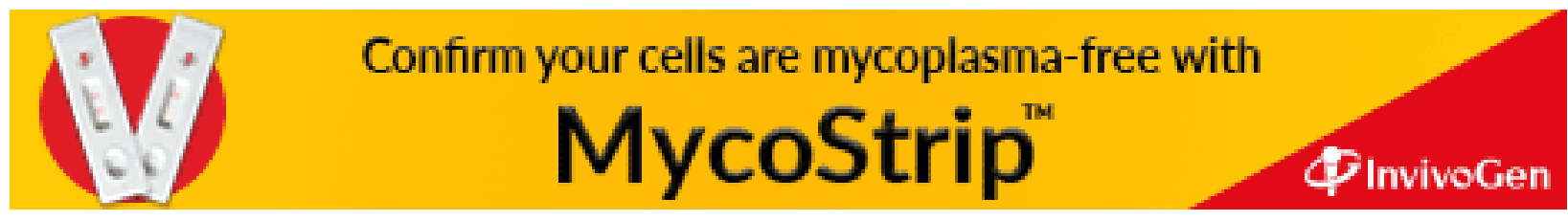

